\title{
Pterygium surgery conjunctival limbal autograft versus amniotic membrane graft. A prospective and comparative study
}

\author{
Sandeep Kumar', Gyan Bhaskar², Bibhuti P Sinha ${ }^{3}$, Anita Ambastha ${ }^{4}$, Aayushi ${ }^{5}$, Rajnee Sinha ${ }^{6}$

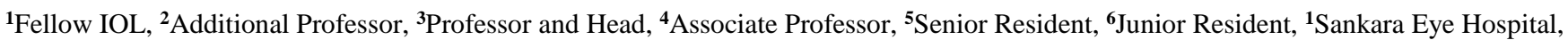 \\ Kanpur, Uttar Pradesh, ${ }^{2-6}$ Regional Institute of Ophthalmology, IGIMS, Patna, Bihar, India
}

\section{*Corresponding Author: Gyan Bhaskar}

Email: drgyan6@gmail.com

\begin{abstract}
Objective To know the outcome of pterygium surgery done by limbal- conjunctival autograft versus amniotic membrane graft using fibrin glue as a bio adhesive. This study was prospective and comparative study done at Regional Institute of Ophthalmology, IGIMS, Patna from July 2014 to June 2017.

Materials and Methods: A prospective study was conducted on 96 patients with primary pterygium. Patients were divided into two groups. Group A and Group B on odd \& even number basis respectively. Group A contains odd numbers of patient, in which limbal-conjunctival autograft was done and Group B pts with even numbers were subjected to amniotic membrane graft with fibrin glue. Patients were followed up on day 1, day 7, 1 month, 3 months and 6 months post-operatively. On each visit recurrence of pterygium, graft retraction, graft displacements, inflammatory reaction and comfort of pat was noted from both the group. Data was collected and analyzed with Microsoft Excel.

Results: Recurrence of pterygium was seen in 3 patients (6.1\%) out of 48 pts. in limbal-conjunctival autograft group A whereas in Group B, it was seen in 4 patients $(8.10 \%)$ out of 48 patients in amniotic membrane graft with fibrin glue group.
\end{abstract}

Keywords: Limbal- conjunctival autograft (LCAG), Amniotic membrane graft (AMG) with fibrin glue, Recurrence.

\section{Introduction}

Pterygium is a degenerative condition of conjunctiva in which triangular wing shaped fibrovascular sub-epithelial ingrowth of conjunctival tissue over the limbus on to the cornea. It is one of the significant cosmetic and disabling ocular problem that may affect young to old aged males or females especially in rural population. Initially it does not affect the vision it may be unilateral or bilateral. Increased prevalence with age, chronic light exposure, chronic irritation, dryness or previous history of trauma. It is believed that the pterygium is a growth disorder characterized by conjunctivalization of the cornea due to localized ultraviolet induced damage to the limbal stem cells. The indications for surgery include. ${ }^{1-3}$

1. Cosmetic purpose,

2. Progressive in nature,

3. Reduced vision due to encroachment of the visual axis and irregular astigmatism,

4. Chronic irritation,

5. Recurrent inflammation,

6. Restriction of ocular motility.

Several surgical modalities have been devised for pterygium excision with variable success rate. Techniques include simple excision, bare sclera technique, free conjunctival membrane technique, transplantation of pterygium in lower fornix (McReynold's technique), limbalconjunctival autograph \& amniotic membrane graft with fibrin glue. Adjunctive treatments include cyclosporine A, thiotepa, mitomycin $\mathrm{C}$, daunorobucin and irradiation to reduce the recurrence rate. The recurrence rate of older techniques has been very high: the ideal surgical procedure for this condition should be simple to perform, fast with an acceptable complication rate and a very low recurrence rate and good prognosis. ${ }^{4-6}$

The structure of the amniotic membrane consists of a single layer of cuboidal nucleated epithelial cells with an underlying basement membrane and stroma. It consists of type $1 \& 4$ collagen. it is well documented for the use in ophthalmology. When used in conjunctival reconstruction, it reduces inflammation on the ocular surface by excluding inflammatory cells with anti-protease activities. Thought to cause apoptosis, has anti-angiogenic properties and also maintain stem populations of the corneal epithelium and the goblet cell precursors in conjunctival epithelium. ${ }^{7,8}$

Initially Fibrin glue is used as a sealant for corneal perforations and muscle surgery. One component consists of a protein solution fibrinogen sealant the other is a thrombin solution. Equal amount of the two components are mixed together, producing a fibrin clot. With the invent of fibrin glue it replaces sutures or reduces the number of sutures required and also reduce the surgical time as well as postoperative complications.

The rationale of this study was to compare the success rate of both the group whether limbal-conjunctival autograft had lower recurrence rate or amniotic membrane graft with fibrin glue had lower recurrence rate.

\section{Material and Methods Study Design}

This study was done at outpatient department of Regional Institute of Ophthalmology, IGIMS, Patna. A total number of 96 patients with pterygium were included in this study. Patients were randomized on odd and even number basis and divided into two groups. Patients with odd numbers were included in Group A $(\mathrm{n}=48)$ treated with Limbal- 
conjunctival autograft (LCAG) and patients of even numbers were treated by amniotic membrane graft with fibrin glue were included in Group B $(n=48)$. Grading of pterygium was done according to TAN Classification, only Grade $2 \&$ above (Encroachment on cornea $>2 \mathrm{~mm}$ ) were taken into consideration.

\section{Inclusion Criteria:}

1. Primary pterygium.

2. Highly motivated patients.

3. Only Grade $2 \&$ above

4. From 20 years to 70 years

\section{Exclusion Criteria:}

1. Patients on multiple medications,

2. Ocular surface disorders,

3. Double pterygium, pterygium with $<2 \mathrm{~mm}$ encroachment on cornea,

4. Known case of glaucoma who could require further filtration surgery

5. Pts. not willing to join the study or not willing to be under long follow up.

6. Recurrence of pterygium.

7. Less than 20years and More than 70 years.

Patients were followed up for at day1, 1 week, 1 month, 3 months and 6 months. On each visit position of graft, displacement, graft retraction, discomfort, foreign body sensation and recurrence was noted. Data were collected and analyzed.

\section{Procedure}

All surgery was done under local anesthesia, initial step of surgical procedure was same in both the Group A and Group B. Pterygium was dissected from corneal to scleral side using 15 No. BP (Bard-Parker) blade \&/or crescent blade to excised the corneal lamellae adjacent to the head of pterygium. Superficial keratectomy was done beneath the pterygium up to the limbus. Conjunctiva was dissected with tenon's capsule and it was excised completely. Sclera is scraped to remove all the tissue then moderate hemostasis was obtained.

In Group A $(n=48)$, ipsilateral Conjunctival autograft was taken from the supero-temporal quadrant of bulbar conjunctiva $0.5 \mathrm{~mm}$ larger than the bared area. Conjunctival graft was prepared and removal of tenon's capsule from the graft was done. Graft was secured and scleral bared area was prepared and dried with cotton swab, freshly prepared fibrin glue was applied over bared area and graft was place in position excess of glue was cut with spring scissor and removed.

In Group B ( $\mathrm{n}=48)$, commercially available wet amniotic membrane was used as Graft. After proper preparation of scleral bared area, freshly prepared fibrin glue was used to oppose the graft with the sclera bed stiches were not used in either of group. After completion of surgery pad and bandage was applied for 24 hours. Post-operatively antibiotic-steroid eye drops was prescribed for 14 day. Caboxymethylcellulose for 15 day oral analgesic SOS patients were followed as per scheduled. The observations thus made were discussed with current available literature and then conclusions were drawn from present study.

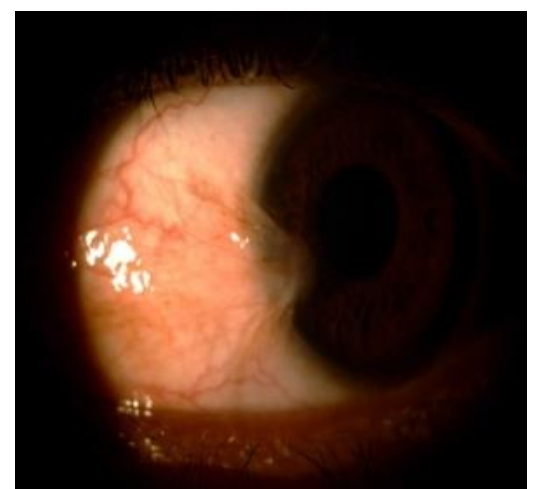

Fig. 1: Pre-operative

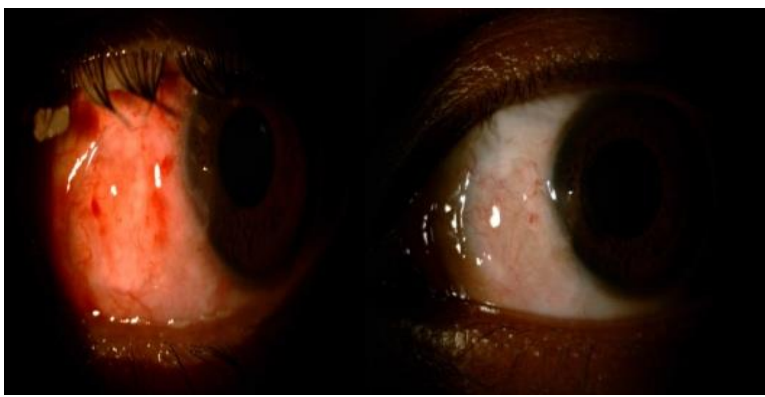

Fig. 2: Post-operative (Group A)

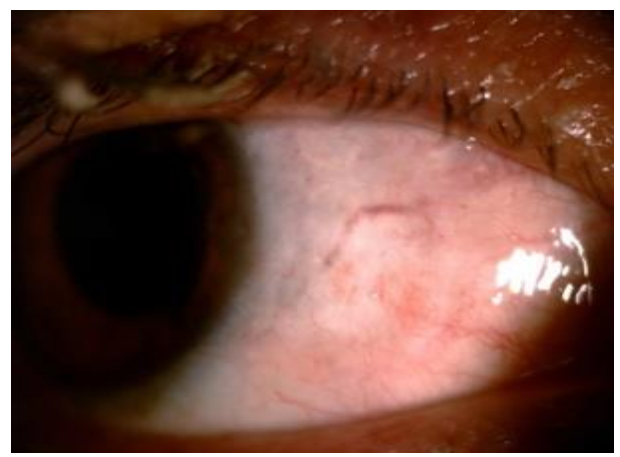

Fig. 3: Post-operative Group B

Study end points: Recurrence of pterygium and follow up completion at 6 months

\section{Statistical Analysis}

The data obtained from this study was analyzed by Microsoft excel. The recurrence rate in each group was measured. Recurrence in males and females in each group was also calculated. Percentage of each grade in each group was calculated. Complications of pterygium surgery such as graft retraction graft displacements, graft edema, pyogenic granuloma and post-operative discomfort was evaluated.

\section{Result}

Out of 48 Patients in Group A, Age of patients ranges from 30 to 65 years, male was 28 and female pt. was 20 and right eye was involved in 22 cases and left eye in 26 cases. Not a single intra operative complication was noted in either of group. In Group B Age of the patients range from 25 to 70, 
male was 30pt.and female was $18 \mathrm{pt}$. right was involve in 23 case and left was involve in 25 pt. Post-operative complication was observe in 3 cases at day 1 in group $\mathrm{A}$, in which two had graft retraction and one had graft displacement (Table 1). in group B complication was observe in 4 cases, one case had loss of amniotic membrane, graft displacement in 2 cases, retraction in one case. Success rate was observed in $93.75 \%$ in group A and 91.665 in Group B.

Table 1: Age wise distribution pterygium

\begin{tabular}{|c|c|c|c|c|}
\hline Age & $\begin{array}{c}\text { Group A } \\
(\mathbf{n = 4 8})\end{array}$ & \% & $\begin{array}{c}\text { Group B } \\
(\mathbf{n = 4 8})\end{array}$ & $\mathbf{\%}$ \\
\hline $20-30$ & 05 & 10.42 & 04 & 8.33 \\
\hline $31-40$ & 09 & 18.75 & 10 & 20.83 \\
\hline $41-50$ & 16 & 33.33 & 18 & 37.5 \\
\hline $51-60$ & 11 & 22.92 & 10 & 20.83 \\
\hline $61-70$ & 07 & 14.58 & 06 & 12.5 \\
\hline
\end{tabular}

Table 2: Group-Post-operative events

\begin{tabular}{|l|c|c|}
\hline \multirow{2}{*}{ Events } & \multicolumn{2}{|c|}{ No. of patient } \\
\cline { 2 - 3 } & Group A & Group B \\
\hline Graft retraction & 2 & 1 \\
\hline Displacement & 1 & 2 \\
\hline Graft edema & 15 & 20 \\
\hline Graft loss & 00 & 1 \\
\hline Infection & 00 & 00 \\
\hline Scleral thinning & 00 & 00 \\
\hline Discomfort & 10 & 15 \\
\hline Granuloma & 00 & 1 \\
\hline
\end{tabular}

Graft edema and granuloma was subsided with time by using topical medications.

Table 3: Failed case management $(n=02)$

\begin{tabular}{|l|c|c|c|}
\hline \multirow{2}{*}{ Events } & \multicolumn{3}{|c|}{ Failed cases } \\
\cline { 2 - 4 } & Group A & Group B & Management \\
\hline Graft retraction & 2 & 1 & $\begin{array}{c}\text { Healed by bare } \\
\text { sclera technique }\end{array}$ \\
\hline Displacement & 1 & 2 & $\begin{array}{c}\text { Healed by bare } \\
\text { sclera technique }\end{array}$ \\
\hline Graft loss & 00 & 1 & $\begin{array}{c}\text { Healed by bare } \\
\text { sclera technique }\end{array}$ \\
\hline Total & 03 & 04 & \\
\hline
\end{tabular}

On $6^{\text {th }}$ month follow up, recurrence of pterygium was seen in 2 males and 1 female in group A whereas it was seen in 2 males and 2 females.

\section{Discussion}

Not a single procedure is full proof for the management of pterygium to prevent the recurrence and complications. It is a big challenge to every ophthalmologist to minimize the recurrence and complication rate of pterygium surgery by introducing novel techniques.

The incidence of pterygium was found to be high in 4150 age group $(n=16,33.33 \%)$ in group $A$ and 18 patients
$37.5 \%$ in group B. It may be due to people have worked outdoors for longer time and hence chances of incidence of pterygium are more in this age group.

Further analysis revealed that pterygium was more common in males in both the groups. Group A included 28 patients $(58.33 \%)$ and Group B included 30 patients (62.5\%). This can be explained by the fact that men work outdoors more than women.

This study is roughly matching with the study done by $\mathrm{P}$ Luanratnokorn, T Ratanopokorn and S Chuck et al (2006) in which they found recurrence rate of $12.3 \%$ in LCAG group and $25 \%$ in AMG group at 6 months follow up. ${ }^{9}$

This study also supports Ahmed Ozar, Sumru Yurdakul et al (2009) in their study found recurrence rate of $14.29 \%$ and $23.08 \%$ in LCAG and AMG with fibrin glue group respectively. ${ }^{10}$

In a study done by P Shashikala et al (2013), ${ }^{11}$ recurrence rate in LCAG and AMG group was $0 \% \& 8 \%$ respectively at 10 months follow up.

Sangwan and Rammurthy et al (2006) ${ }^{12}$ in a study of 86 patients with 44 eyes with LCAG and 42 eyes with AMG with fibrin glue or sutures found recurrence of $9 \%$ and $13 \%$ respectively. Mean follow up was 6 months.

So, as presented in various studies (Review of literature) there are some differences in the recurrence rate of pterygium between two groups whereas some studies have more or less same recurrence rates between two groups.

\section{Limitations}

Only 6 months follow up. Most of the patients belonged to more or less same geographical and environmental conditions. Occupation was not taken in data. So, these factors could influence the surgical outcome of our study.

\section{Conclusion}

As limbal-conjunctival autograft has relatively low recurrence rate and as is easy to harvest hence, it is the preferred choice in pterygium surgery. Although amniotic membrane graft with fibrin glue also can be used as an alternative for large double headed pterygium or for pts. Who may require glaucoma filtration surgeries.

\section{Source of Funding: Self}

\section{Conflict of Interest: None}

\section{Ethical Clearance: Taken}

\section{References}

1. Qai A Faijo, Alan Sugar, Pterygium and conjunctival degenerations. In: Yanoff \& Duker Ophthalmology, $3^{\text {rd }}$ ed. Mosby Elsevier; 2009. p248-249.

2. Michaeline A Isawumi, Mustapha B Hassan, Esther Aseku Olarinmoye, Patience O Akinwuci, Wasiu O Adebimpe, Christopher Alebiosu. Prevalance and causes of ocular morbidity seen among rural adult population of Osun State Southwest Nigeria. 2013;6(4):465-71. 
3. Sonia Puri, Munish Ashat, Sandeep Singh, Tarundeep Kaur, Akshay Kumar. Pattern \& distribution of ocular morbidity in patients visiting the field practice area of tertiary care hospital in North India. J Biomed Pharm Res 2013;42-6.

4. Ana Torres Gimeno, Luci Martinez-Costa, Guillermo Ayala. Preoperative factors influencing success in pterygium surgery. BMC Ophthal 2012;12-38.; doi10.1186/1471-2415-12-38

5. Sandeep Saxena. Clinical Ophthalmology: Medical \& Surgical Approach. $2^{\text {nd }}$ ed. Jaypee Highlights Medical Publishers; 2002.p77-82

6. Sandeep Saxena. Clinical Ophthalmology: Medical\& Surgical Approach. $2^{\text {nd }}$ ed. Jaypee Highlights Medical Publishers; 2002.p101-105

7. Prabhasawat P, Bastonk, Burkett G, Tseng SC. Comparison of Conjunctival autograft, amniotic membrane graft and primary closure for pterygium excision. (pubMed-NCBI). 1997;104(6):85-97.

8. Virendra S Sangwan, Sanghamitra Burman, Sushma Tejvani, Sankaranarayana Pilla I Mahesh, Ramesh Murthy. Amniotic Membrane Transplantation: A review of current indications. Indian J Ophthal 2007;55(4):257-60.

9. P Luanratanokorn, T Ratanapokorn, O Suwan-apichon \& S Chuck. Randomized controlled study of conjunctivalautograft $\mathrm{v} / \mathrm{s}$ amniotic membrane graft in pterygium excision. $\mathrm{Br} \mathrm{J}$ Ophthalmol 2006;90(12):1476-80.
10. Ozer, Ahmet \& Yildirim, Nilgun \& Erol, Nazmiye \& Yurdakul, Sumru. (2009). Long-Term Results of Bare Sclera, Limbal-Conjunctival Autograft and Amniotic Membrane Graft Techniques in Primary Pterygium Excisions. Ophthalmologica. Journal international d'ophtalmologie. International journal of ophthalmology. Zeitschrift für Augenheilkunde 2009;223:26973. 10.1159/000210444.

11. P Shashikala. Is amniotic membrane transplantation, an adjuvant of choice following excision of primary pterygium? $J$ Clin Ophthalmol Res 2013;1(2):91-3.

12. Sangwan, Virender \& B, Ramamurthy \& SG, Dattar. Evaluation of outcome of amniotic membrane transplantation with conjunctival limbal autograft for Pterygium. Asian J Ophthalmol 2006;8.

How to cite this article: Kumar S, Bhaskar G, Sinha BP, Ambastha A, Aayushi, Sinha R. Pterygium surgery conjunctival limbal autograft versus amniotic membrane graft. A prospective and comparative study. Int J Ocul Oncol Oculoplasty 2019;5(2):86-9. 